\title{
Antisense ACC Oxidase RNA Delays Carnation Petal Senescence
}

\author{
Keith W. Savin ${ }^{1}$, Stanley C. Baudinette, Michael W. Graham, Michael Z. Michael, Greg D. Nugent, \\ Chin-Yi Lu, Stephen F. Chandler, and Edwina C. Cornish \\ Florigene Pty, 16 Gipps Street, Collingwood, Australia 3066
}

The phytohormone ethylene is essential for senescence in many fruits and flowers. In the biosynthesis of ethylene in plants, the conversion of $S$-adenosyl methionine (SAM) to 1-aminocyclopropane1-carboxylic acid (ACC) and the conversion of ACC to ethylene are catalyzed by ACC synthase (ACS) and ACC oxidase (ACO), respectively (Adams and Yang, 1979). Using a cDNA clone representing carnation ACO (from Dianthus caryophyllus L. cv. Scania), we have produced transgenic carnation plants containing an antisense ACO gene. Flowers of one transformant from each of two cultivars ('Scania' and 'White Sim') containing this antisense gene exhibit low climacteric ethylene production and a markedly delayed petal senescence. At the time after harvest when petal inrolling would normally take place, the antisense ACO flowers produce little or no detectable ACO mRNA or ACS mRNA. However, the ACS and ACO genes can be induced in these flowers by applying exogenous ethylene.

\section{CARNATION ACC OXIDASE}

The species D. caryophyllus has been used for many years as a model system for studying the physiology of flower senescence (Cook and van Staden, 1988; Reid and $\mathrm{Wu}, 1992$ ). Petal senescence in carnation is an active process involving many biochemical and physiological changes and includes the expression of genes not expressed in other parts of the plant. The process appears to be regulated by ethylene. The petals exhibit a characteristic "inrolling" behavior during senescence and in response to exogenous ethylene. The inrolling can be delayed or prevented by inhibitors of ethylene synthesis, such as amino-oxyacetic acid (Fujino et al., 1980).

During a study of gene expression in carnation petal, we used differential hybridization to identify several senescence-associated cDNA clones. A cDNA library had been constructed using mRNA from inrolling 'Scania' carnation petals and the Lambda Zap cDNA cloning vector. It was probed with ${ }^{32} \mathrm{P}$-labeled cDNA from inrolling petal, day 0 petal, and leaf. The DNA sequence of one of the clones detected predominantly by the inrolling petal probe (clone pCGP363, $1171 \mathrm{bp}$ ) had $68 \%$ homology to the DNA sequence of a tomato (Lycopersicon esculentum Mill.) cDNA clone, pTOM13, associated with ethylene production and fruit ripening. Later, pTom13 was identified as encoding ACC oxidase (Hamilton et al., 1991; Holdsworth et al., 1987; Spanu et al., 1991). The deduced amino acid sequence of 321 amino acids shares $68 \%$ identity with the tomato ACO amino acid sequence (Holdsworth et al., 1987), 70\% identity with avocado (Persea americana Mill.) ACO (McGarvey et al., 1992), and >99\% identity with the ACO sequence from another cultivar of carnation, 'White Sim' (Wang and Woodson, 1991). The 'Scania' sequence differs from that of 'White Sim' only at amino acid residue 147. An alanine in the 'White Sim' sequence is replaced by a glycine in the 'Scania' sequence. The DNA sequence of the 'Scania' ACO cDNA clone has been submitted to Genbank (L35152; DINACCA). Northern analysis has shown expression of the ACO gene in many tissues of carnation, including high levels of expression in inrolling petals (Woodson et al., 1992; S.C.B., unpublished data).

Received for publication 1 Feb. 1995. Accepted for publication 16 Feb. 1995 We thank Alison Kellow, Ann Bayly, Ellen O'Connor, Kim Stevenson, and Allan Simmons for technical assistance. We also thank Robert Ludwig, Univ. of California, Santa Cruz, for providing the Ag10 strain of Agrobacterium tumefaciens. We also gratefully acknowledge the Australian Dept. of Industry, Science, and Technology for partly funding this project (Industry, Research, and Develpoment Board Generic Technology Grants Scheme, agreement no. 14021).

${ }^{1}$ To whom reprint requests should be addressed.

\section{TRANSGENIC CARNATION}

To create a carnation line with low ethylene synthesis and delayed petal senescence, and to more clearly define the role of ethylene in the senescence of carnation petals, we generated transgenic carnation plants producing antisense ACO RNA. Antisense RNA complementary to mRNA encoding ACO has been used to reduce ethylene synthesis and delay fruit ripening in transgenic tomato (Hamilton et al., 1990). Therefore, we constructed a T-DNA-based expression vector for the production of antisense ACO RNA in plants. This vector (pCGP407) was constructed using the standard techniques described in Sambrook et al. (1989). The carnation ACO cDNA fragment, contained within pCGP363, was inserted in reverse orientation into a binary expression vector, pCGP293 (Brugliera et al., 1994), between the MAC promoter (Comai et al., 1990) and the mas 3' end (from the Agrobacterium mannopine synthase gene). According to Comai et al. (1990), MAC is a strong constitutive promoter. In transgenic carnation, we have confirmed that the MAC promoter is able to direct expression of a reporter gene (uidA) in leaf, stem, and all floral tissues (data not shown). Using the Agrobacterium-based transformation method of Lu et al. (1991), we produced nine 'Scania' and 36 'White Sim' carnation plants containing the antisense ACO gene. The section of DNA transferred to the plant genome by the binary vector pCGP407 contained the neomycin phosphotransferase (NPT II) gene, in addition to the antisense ACO gene, thus allowing selection of transgenic shoots by growth on kanamycin.

Southern analysis (Sambrook et al., 1989) of the transgenic carnation plants, using a DNA fragment containing the neomycin phosphotransferase (NPT II) coding sequence as a probe, indicated the presence of at least one copy of the introduced genes in those plants selected for growth on kanamycin. For an analysis of the DNA from some of these plants, leaf tissue was ground in liquid nitrogen and the DNA extracted using guanidine isothiocyanate and precipitated with ethanol. For Southern analysis, the DNA was cut with the restriction enzyme Hind III. The Southern blot was probed with a ${ }^{32} \mathrm{P}$-labeled Eco RIDNA fragment from a clone of the NPT II gene. Filters were washed in $0.1 \times$ SSC at 65 C. Of special interest are the 'Scania' plant \#705 with five copies of the NPT II gene (and therefore presumably of the antisense ACO gene also) and a 'White Sim' plant, \#2373B, which has a single copy of NPT II (Fig. 1).

\section{FLOWERS WITH DELAYED SENESCENCE}

Plants \#705 and \#2373B produced flowers that failed to display the inrolling behavior typical of carnation flower senescence. The normal vase life of 'Scania' and 'White Sim' flowers was $\approx 5$ days from day of harvest to inrolling. Flowers from \#705 and \#2373B had a vase life of 8 to 9 days, after which the petals slowly discolored and dessicated. All other plants produced flowers of normal senescence phenotype. The vase life of flowers, in distilled water, with a stem $\approx 20 \mathrm{~cm}$ long, was measured at $21 \mathrm{C}$, with overhead lighting at $\approx 12 \mu \mathrm{mol} \cdot \mathrm{m}^{-2} \cdot \mathrm{s}^{-1}$ photon flux density, using a 12-h photoperiod. At day 0 (day of harvest), the outer petals had opened so that they were at $90^{\circ}$ to the stem (in a commercial operation, flowers are harvested much earlier than this). Flowers of plant \#705 had a slightly altered morphology—reduced petal count and pigmentation being the predominant effects. 'White Sim' plant \#2373B, however, produced flowers with normal flower morphology. A day-8 \#2373B flower was still attractive, while a day8 flower from a nontransgenic 'White Sim' control plant had senesced (Fig. 2).

Measurements of ethylene production, using a gas chromatograph (model 3300; Varian, Mulgrave, Australia) equipped with a Porapak 
$\mathrm{N}$ column (80C), flame ionization detector, and Varian 4400 integrator, indicated that flowers of \#705 and \#2373B had a greatly reduced capacity to produce ethylene. All plants except \#705 and \#2373B produced flowers that synthesized normal amounts of ethylene, showing the expected climacteric rise in ethylene production at the onset of inrolling. Flowers of \#705 and \#2373B plants produced $<10 \%$ of the level of ethylene produced by control (nontransgenic) flowers (Fig. 3).

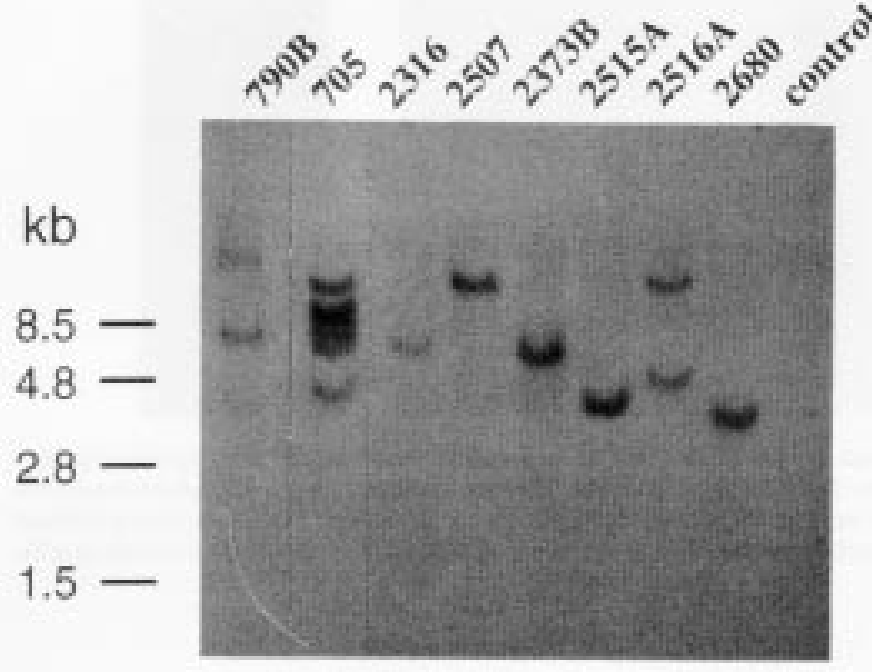

Fig. 1. Southern analysis of DNA from transgenic carnations. HindIII-cut DNA $(\approx 10 \mu \mathrm{g} /$ lane $)$ was electrophoresed in a $0.8 \%$ agarose gel and probed with a DNA fragment containing the NPT II gene.

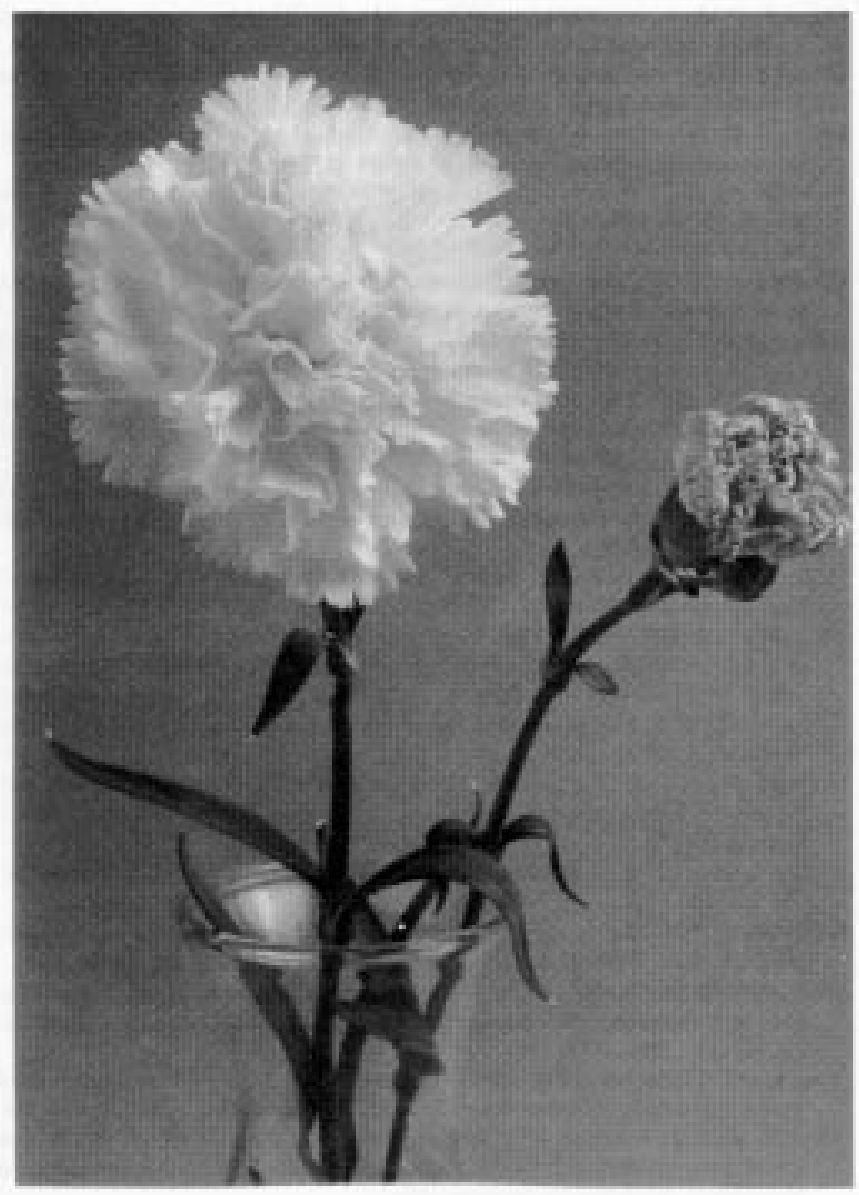

Fig. 2. A flower from (left) transformant \#2373B and (right) nontransgenic 'White Sim' control carnations, both flowers are day- 8 postharvest.

\section{ACO AND ACS GENE EXPRESSION}

Analysis of the mRNA of normal carnation plants has previously indicated the presence of ACS mRNA and ACO mRNA in many tissues, but especially in senescing petals where there is a substantial peak of mRNA accumulation and enzyme activity during the climacteric phase of petal senescence (Woodson et al., 1992). We have analyzed total RNA from the petals of transgenic carnations using strand-specific RNA probes for detecting ACO mRNA and antisense RNA from the inserted gene, and used a carnation petal ACS cDNA clone (Michael et al., 1992; European Molecular Biology Laboratory nucleotide sequence database accession number Z18952) for detecting ACS mRNA. After grinding under liquid nitrogen, total RNA was extracted from petals using guanidine isothiocyanate, further purified using a $\mathrm{CsCl}$ cushion, and subjected to standard Northern analysis (described in Sambrook et al., 1989). After hybridization, all filters were washed under high stringency conditions $(0.1 \times \mathrm{SSC}, 65 \mathrm{C})$ before visualization with X-ray film. On a Southern blot under these conditions, a single strongly hybridizing ACO gene is detected. DNA fragments, possibly from other weakly hybridizing ACO gene sequences, are visible after longer exposure of the X-ray film. Only a single ACS gene is detected. Northern analysis (Fig. 4) indicated that petals from \#705 and \#2373B produce only low levels of ACO and ACS mRNA at the time when inrolling would occur in normal flowers (days 4 to 6 ).

Previous physiological and biochemical work (Overbeek and Woltering, 1990; Wang and Woodson, 1989) suggested that activation of ACS and ACO genes of carnation petals requires the presence of ethylene, possibly diffusing from the gynoecium or style. Our Northern analysis data confirm that, in the absence of ethylene, there is little or no accumulation of mRNA of either ACO or ACS genes. This finding was suggested previously by inhibitor studies (Woodson et al., 1992). As a further test, we treated the ACO-suppressed flowers with ethylene. Exposure of day-4 flowers from plants \#705 and \#2373B to exogenous ethylene gas $(150 \mathrm{ppm})$ for $18 \mathrm{~h}$ at $21 \mathrm{C}$ induced immediate inrolling of petals. (The same result can be achieved using ethylene at $10 \mathrm{ppm}$.) Analysis of the petal RNA from these treated flowers demonstrated that the ACS and ACO genes were induced in response to exogenous ethylene (Fig. 4). The ACS mRNA accumulated to similar levels in \#705 and \#2373B flowers. Despite the presence of the antisense ACO transgene, the ACO mRNA level did rise in response to exogenous ethylene, although to a much lower level than was seen in nontreated, senescing control flowers (Fig. 4). There was a marked difference in the levels of ethylene-induced production of ACO mRNA between \#705 and \#2373B.

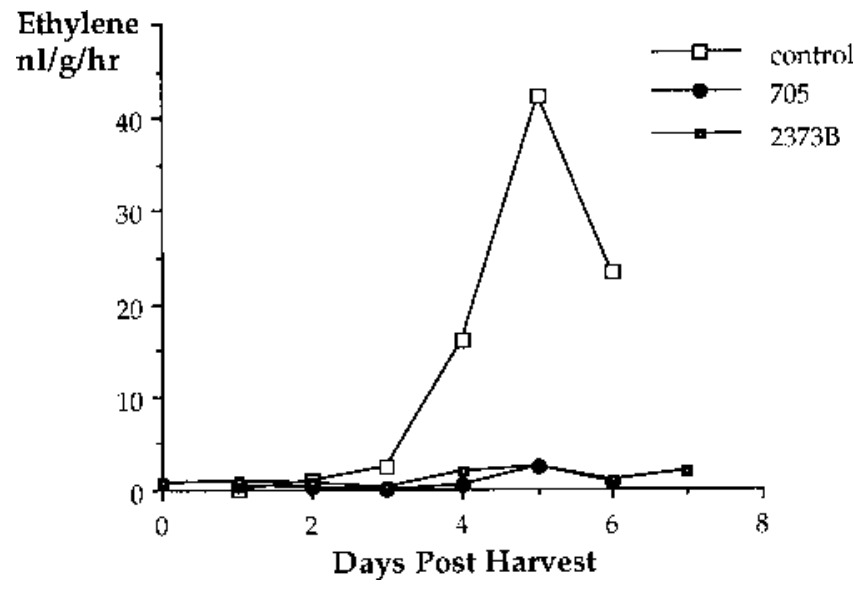

Fig. 3. Ethylene production of control and transformed (\#705 and \#2373B) carnation flowers (not including stem). Flowers were placed in a gas-tight chamber for $3 \mathrm{~h}$ each day after harvest. The ethylene content of a gas sample taken from the chamber was measured using gas chromatography, as described in the text. The control values are the average of the ethylene measurements from nine individual flowers. The \#705 and \#2373B values are averaged from three flowers each. 

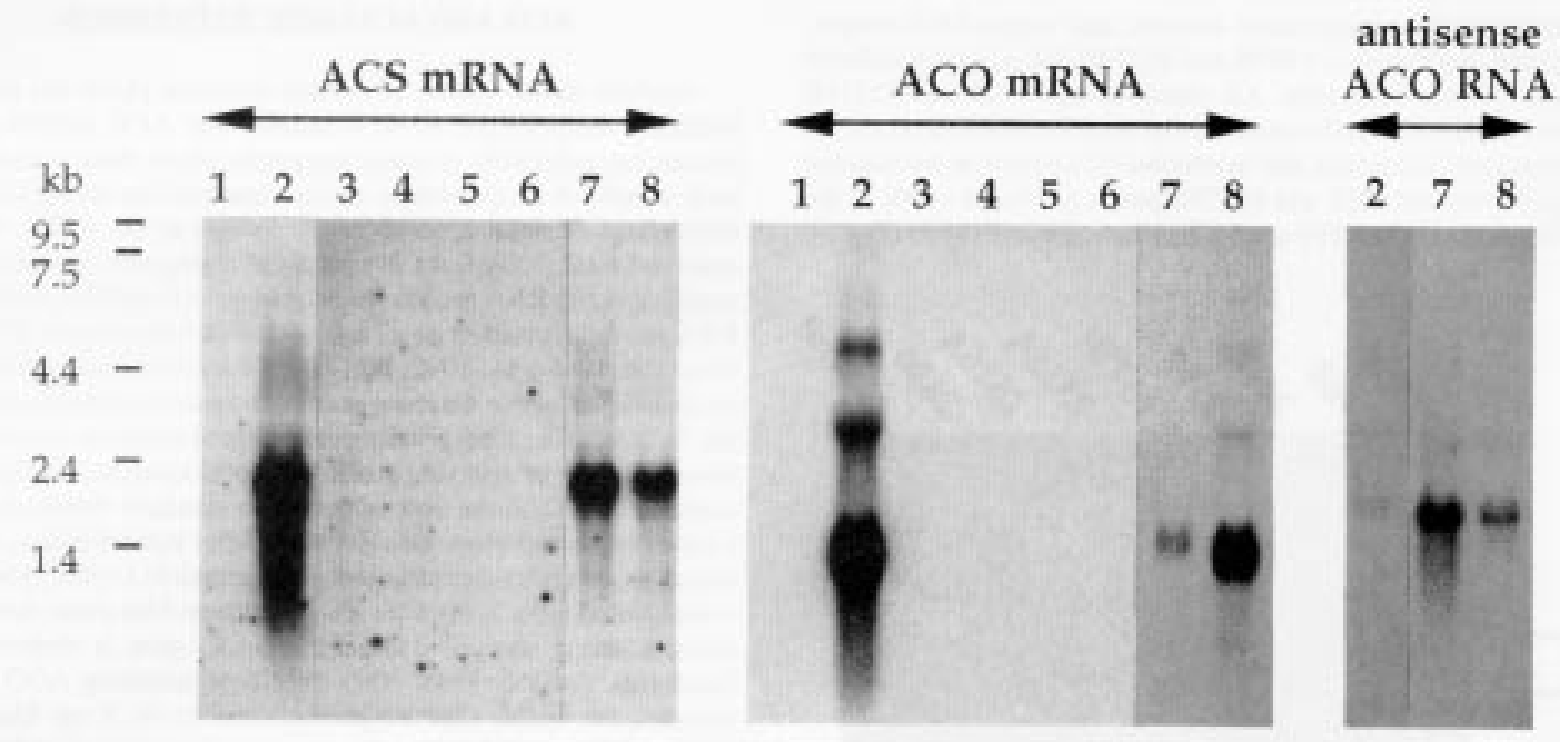

Fig. 4. Northern analysis of ACS and ACO mRNA and ACO antisense RNA in carnation petals. Total RNA (10 $\mu \mathrm{g} / \mathrm{lane})$ was analyzed from day 0 petals of control (lane 1), \#705 (lane 3), and \#2373B (lane 5) flowers; day-5 petals of control (lane 2), \#705 (lane 4), and \#2373B (lane 6) flowers. Also analyzed was total RNA isolated from \#705 (lane 7) and \#2373B (lane 8) day-5 flowers, which had been exposed to ethylene (150 ppm) for the preceding $18 \mathrm{~h}$. Filters were hybridized with (left) an ACS cDNA fragment to detect ACS mRNA; (center) a strand-specific antisense RNA probe to detect ACO mRNA; and (right) a strand-specific sense ACO RNA probe to detect antisense ACO RNA.

Further investigation of the induction of ACO mRNA in the transgenic flowers revealed an inverse correlation between the level of antisense RNA present in the petals and the accumulation of ACO mRNA. Hybridizing a Northern blot of RNA from ethylene-treated petals, with a sense-specific probe for detection of antisense RNA, indicated that \#705 petals produced more antisense RNA than did petals of \#2373B (Fig. 4). A similar result was found using the RNA from three separate flowers of each of the two transgenic lines.

In the antisense ACO flowers, the exogenous ethylene is able to partially overcome the antisense-induced block in mRNA accumulation (by boosting ACO gene transcription), or it induces transcription of an ethylene-responsive ACO gene different from that being repressed by the antisense RNA. The high stringency used for detection makes the latter unlikely, but not impossible. Little is known of the presumptive $\mathrm{ACO}$ gene family in carnation. Whatever the mechanism, these data indicate that antisense relies on the quantity of antisense RNA present in the cell for its effectiveness.

\section{CONCLUSIONS}

Two observations can be made here: 1) The antisense ACO gene has succeeded in suppressing the level of ACO mRNA and, hence, has all but eliminated ethylene production and extended carnation flower vase life. 2) As suggested by earlier physiological data, expression of the ACS and ACO genes in petals must be dependent on the presence of ethylene. Northern analysis data illustrate, at a molecular level, the so-called "autocatalytic" production of ethylene during carnation petal senescence. That is, a positive feedback loop exists in which ethylene induces expression of at least the ACS and ACO enzymes in the ethylene biosynthesis pathway. In flowers from the transgenic plants, the degree to which the ACO mRNA can accumulate in response to ethylene is restricted by the amount of antisense ACO RNA present. Our transgenic plants, in which expression of the ACO gene has been all but eliminated, will be useful tools for further analyzing the various molecular and physiological processes influenced by the phytohormone ethylene in carnation. The stability of antisense gene suppression during propagation of a commercial crop, such as carnation, also should be investigated.

The generation of transgenic carnation plants in which the ability to synthesize ethylene has been reduced or eliminated by use of the antisense technique reflects similar findings in tomato and reinforces the concept of improving properties, such as postharvest qualities, by genetic engineering rather than by long-term classical breeding or the application of chemicals.

\section{Literature Cited}

Adams, D.O. and S.F. Yang. 1979. Ethylene biosynthesis: Identification of 1aminocyclopropane-1-carboxylic acid as an intermediate in the conversion of methionine to ethylene. Proc. Natl. Acad. Sci. USA 76:170-174.

Brugliera, F., T.A. Holton, T.W. Stevenson, E. Farcy, C-Y. Lu, and E.C. Cornish. 1994. Isolation and characterization of a cDNA clone corresponding to the $R t$ locus of Petunia hybrida. Plant J. 5:81-92.

Comai, L., P. Moran, and D. Maslyar. 1990. Novel and useful properties of a chimeric plant promoter combining CaMV 35S and MAS elements. Plant Mol. Biol. 15:373-381.

Cook, E.L. and J. van Staden. 1988. The carnation as a model for hormone studies in flower senescence. Plant Physiol. Biochem. 26:793-807.

Fujino, D.W., M.S. Reid, and S.F. Yang. 1980. Effects of amino-oxyacetic acid on postharvest characteristics of carnation. Acta Hort. 113:59-64.

Hamilton, A.J., M. Bouzayen, and D. Grierson. 1991. Identification of a tomato gene for the ethylene-forming enzyme by expression in yeast. Proc. Natl. Acad. Sci. USA 88:7434-7437.

Hamilton, A.J., G.W. Lycett, and D. Grierson. 1990. Antisense gene that inhibits synthesis of the hormone ethylene in transgenic plants. Nature 346:284-287.

Holdsworth, M.J., C.R. Bird, J. Ray, W. Schuch, and D. Grierson. 1987. Structure and expression of an ethylene-related mRNA from tomato. Nucleic Acids Res. 15:731-739.

Lu, C-Y., G. Nugent, T. Wardley-Richardson, S.F. Chandler, R. Young, and M.J. Dalling. 1991.Agrobacterium-mediated transformation of carnation (Dianthus caryophyllus). Bio/Technology 9:864-868.

McGarvey, D.J., R. Sirevag, and R.E. Christoffersen. 1992. Ripening-related gene from avocado fruit: Ethylene-inducible expression of the mRNA and polypeptide. Plant Physiol. 98:554-559.

Michael, M.Z., K.W. Savin, S.C. Baudinette, M.W. Graham, S.F. Chandler, C-Y. Lu, C. Caesar, I. Gautrais, Y. Young, G.D. Nugent, K.R. Stevenson, E.L-J. O'Connor, C.S. Cobbett, and E.C. Cornish. 1992. Cloning of ethylene biosynthetic genes involved in petal senescence of carnation and petunia, and their antisense expression in transgenic plants, p. 298-303. In: J.C. Pech, A. Latche, and C. Balague (eds.). Cellular and molecular aspects of the plant hormone ethylene. Kluwer Academic Publishers, Dordrecht, The Netherlands.

Overbeek, J.H.M. and E.J. Woltering. 1990. Synergistic effect of 1-aminocyclopropane1-carboxylic acid and ethylene during senescence of isolated carnation petals. Physiol. Plant. 79:368-376.

Reid, M.S. and M-J. Wu. 1992. Ethylene and flower senescence. Plant Growth Regulat. 11:37-43.

Sambrook, J., E.F. Fritsch, and T. Maniatis. 1989. Molecular cloning: A laboratory manual. 2nd ed. Cold Spring Harbor Laboratory Press, Cold Spring Harbor, N.Y.

Spanu, P., D. Reinhardt, and T. Boller. 1991. Analysis and cloning of the ethylene-forming enzyme from tomato by functional expression of its mRNA in Xenopus laevis oocytes. EMBO J. 10:2007-2013.

Wang, H. and W.R. Woodson. 1989. Reversible inhibition of ethylene action and interruption of petal senescence in carnation flowers by norbornadiene. Plant Physiol. 89:434-438.

Wang, H. and W.R. Woodson. 1991. A flower senescence-related mRNA from carnation shares sequence similarity with fruit ripening-related mRNAs involved in ethylene biosynthesis. Plant Physiol. 96:1000-1001.

Woodson, W.R., K.Y. Park, A. Drory, P.B. Larsen, and H. Wang. 1992. Expression of ethylene biosynthetic pathway transcripts in senescing carnation flowers. Plant Physiol. 99:526-532. 